\title{
Vertical variation of optical properties of mixed Asian dust/pollution plumes according to pathway of air mass transport over East Asia
}

\author{
S.-K. Shin ${ }^{1, *}$, D. Müller ${ }^{2, * *}$, C. Lee ${ }^{3}$, K. H. Lee ${ }^{4}$, D. Shin ${ }^{5}$, Y. J. Kim ${ }^{1}$, and Y. M. Noh \\ ${ }^{1}$ School of Environmental Science and Engineering, Gwangju Institute of Science \& Technology, Gwangju, \\ Republic of Korea \\ ${ }^{2}$ School of Physics, Astronomy and Mathematics, University of Hertfordshire, Hertfordshire, UK \\ ${ }^{3}$ Korea Meteorological Administration, Seoul, Republic of Korea \\ ${ }^{4}$ Department of Atmospheric and Environmental Sciences, Gangneung-Wonju National University, Gangneung, \\ Republic of Korea \\ ${ }^{5}$ Air Quality Forecasting Centre, Climate and Air Quality Research Department, National Institute of Environmental \\ Research, Incheon, Republic of Korea \\ ${ }^{6}$ International Environmental Research Centre (IERC), Gwangju Institute of Science \& Technology, Gwangju, \\ Republic of Korea \\ * now at: Department of Atmospheric and Environmental Sciences, Gangneung-Wonju National University, Gangneung, \\ Republic of Korea \\ ** formerly at: School of Environmental Science and Engineering, Gwangju Institute of Science \& Technology, Gwangju, \\ Republic of Korea
}

Correspondence to: Y. M. Noh (nym@gist.ac.kr)

Received: 24 December 2014 - Published in Atmos. Chem. Phys. Discuss.: 6 February 2015

Revised: 20 May 2015 - Accepted: 21 May 2015 - Published: 17 June 2015

\begin{abstract}
We use five years (2009-2013) of multiwavelength Raman lidar measurements at Gwangju, South Korea $\left(35.10^{\circ} \mathrm{N}, 126.53^{\circ} \mathrm{E}\right)$ for the identification of changes of optical properties of East Asian dust depending on its transport path over China. Profiles of backscatter and extinction coefficients, lidar ratios, and backscatter-related Ångström exponents (wavelength pair 355/532 nm) were measured at Gwangju. Linear particle depolarization ratios were used to identify East Asian dust layers. We used backward trajectory modeling to identify the pathway and the vertical position of dust-laden air masses over China during long-range transport. Most cases of Asian dust events can be described by the emission of dust in desert areas and subsequent transport over highly polluted regions of China. The Asian dust plumes could be categorized into two classes according to the height above ground at which these plumes were transported: (case I) the dust layers passed over China at high altitude levels ( $>3 \mathrm{~km}$ ) until arrival over Gwangju, and (case II) the Asian dust layers were transported near the surface and within the lower troposphere $(<3 \mathrm{~km})$ over industrialized ar-
\end{abstract}

eas before they arrived over Gwangju. We find that the optical characteristics of these mixed Asian dust layers over Gwangju differ depending on their vertical position above ground over China and the change of height above ground during transport. The mean linear particle depolarization ratio was $0.21 \pm 0.06$ (at $532 \mathrm{~nm}$ ), the mean lidar ratios were $52 \pm 7 \mathrm{sr}$ at $355 \mathrm{~nm}$ and $53 \pm 8 \mathrm{sr}$ at $532 \mathrm{~nm}$, and the mean Ångström exponent was $0.74 \pm 0.31$ for case I. In contrast, plumes transported at lower altitudes (case II) showed low depolarization ratios $(0.13 \pm 0.04$ at $532 \mathrm{~nm})$, and higher lidar ratio $(63 \pm 9 \mathrm{sr}$ at $355 \mathrm{~nm}$ and $62 \pm 8 \mathrm{sr}$ at $532 \mathrm{~nm})$ and Ångström exponents $(0.98 \pm 0.51)$. These numbers show that the optical characteristics of mixed Asian plumes are more similar to optical characteristics of urban pollution. We find a decrease of the linear depolarization ratio of the mixed dust/pollution plume depending on transport time if the pollution layer traveled over China at low heights, i.e., below approximately $3 \mathrm{~km}$ above ground. In contrast, we do not find such a trend if the dust plumes traveled at heights above $3 \mathrm{~km}$ over China. We need a longer time series of lidar measure- 
ments in order to determine in a quantitative way the change of optical properties of dust with transport time.

\section{Introduction}

Desert dust is the most abundant natural source of atmospheric particles over land. Its light-absorption capacity is strong in the ultraviolet regions of the solar spectrum (Jacobson, 2012). The light-absorption capacity depends on the proportions of $\mathrm{Fe}_{2} \mathrm{O}_{3}, \mathrm{Al}_{2} \mathrm{O}_{3}, \mathrm{SiO}_{2}, \mathrm{CaCO}_{3}, \mathrm{MgCO}_{3}$ (s), clays, and other substances. The transport patterns of dust over North Africa and East Asia as well as the vertical distribution of dust change intra- and inter-annually. Thus the influence of dust on the atmosphere's radiation balance is complex (Griggs and Noguer, 2002; Mahowald et al., 2006; Durant et al., 2009). Central East Asia has large desert regions. Asian dust particles that originate from the Taklamakan desert in western China and the Gobi desert in Mongolia and northwest China (Fig. 1) influence the regional climate over East Asia and can be found as far as the western coast of North America (Husar et al., 2001; McKendry, 2001; Huang et al., 2008). East Asian dust is particularly complicated as it usually travels over densely populated and highly industrialized areas of China before it moves out over Pacific Ocean. During transport over East Asia dust mixes with pollutants such as industrial soot, toxic material, and acidic gases (Sun et al., 2005).

Field campaigns, such as ACE-Asia (Huebert et al., 2003) and ADEC (Mikami et al., 2006), have significantly added to our knowledge of the radiative effects of Asian dust. Carrico et al. (2003) and Yu et al. (2006) found differences in dust optical properties as the result of the mixing of dust with anthropogenic pollution between source regions of dust and observation sites downwind of its source regions. The mixing between Asian dust and industrial pollutant particles has significant influence on the size distribution and the chemical composition of aerosol plumes (Wang et al., 2007; Sun et al., 2010).

There exist few studies on the degree of mixing that occurs between dust and pollution during transport, the effect of the direction of dust transport across China, and the vertical distribution of Asian dust layers during long-range transport over China. There still is a lack of understanding of how much of the mixing of dust with pollutants depends on the vertical distribution of dust when it passes over source regions of anthropogenic pollution in East Asia. One reason of our limited knowledge is that there are only few vertically resolved, long-term observations of pollution over East Asia.

Lidar (light detection and ranging) is a powerful technique for measuring the vertical distribution of atmospheric aerosols with high temporal and spatial resolution. In this study we use Raman lidar data taken at Gwangju, South Korea, between 2009 and 2013. In our study we focus specifically on lidar observations of Asian dust layers as they

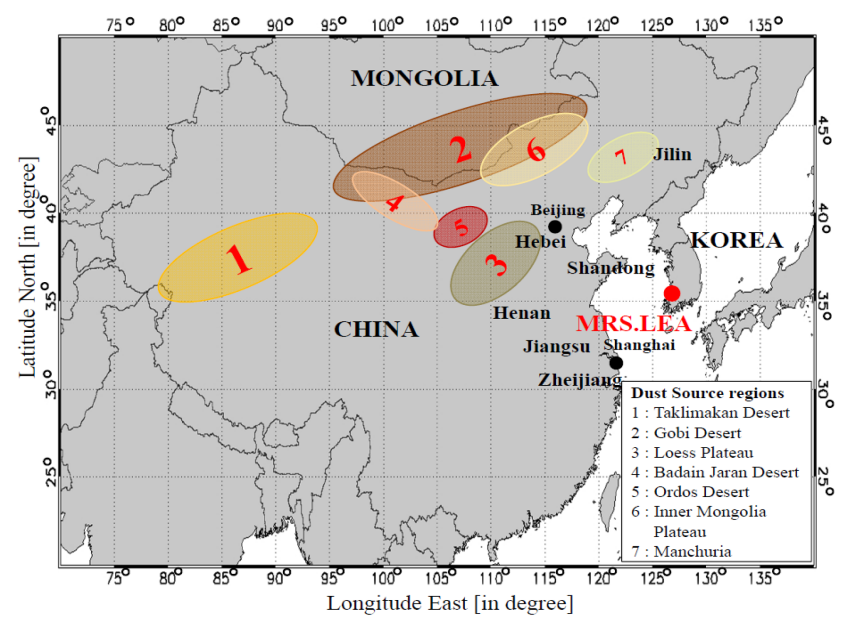

Figure 1. Map of the desert regions (Taklimakan, Gobi, Badain Jaran, Ordos, Inner Mongolia plateau, and Manchuria) and loess regions (Loess Plateau and Manchuria). The location of some major cities (Beijing and Shanghai) and industrialized areas of China (Hebei, Shandong, Henan, and Zhejiang province) is also shown. MRS.LEA is located in Gwangju, South Korea.

passed over China. We use backward trajectory analysis with the HYSPLIT (HYbrid Single Particle Lagrangian Integrated Trajectory) (Draxler and Rolph, 2003) model to identify the transport pathway and the vertical distribution of the Asian dust layers during long-range transport.

The main objective of this study is to investigate the variation of optical properties of mixtures of Asian dust with anthropogenic pollution depending on the pathways and vertical distributions of these mixed dust layers during long-range transport. In this contribution, we used the linear particle depolarization ratio to identify these dust layers. We present vertically resolved optical properties such as lidar ratio and the Ångström exponent.

Section 2 presents the methods used in this study. Section 3 presents our results. We discuss our results and summarize our findings in Sect. 4.

\section{Methodology}

\subsection{GIST Multiwavelength Raman lidar}

The lidar station, dubbed MRS.LEA (Multiwavelength Raman Spectrometer Lidar in East Asia) of the Gwangju Institute of Science and Technology (GIST) is located at $35.10^{\circ} \mathrm{N}, 126.53^{\circ} \mathrm{E}$ in the west-southwestern part of the Korean peninsula (Fig. 1).

A description of the lidar system is given by Noh et al. (2007, 2008). The light source of the lidar is a pulsed Nd:YAG laser that emits light pulses at 355, 532, and $1064 \mathrm{~nm}$. The laser output power is 140,154 , and $640 \mathrm{~mJ}$ at the three emission wavelengths, respectively. The pulse rep- 
etition rate is $10 \mathrm{~Hz}$. We use a beam expander at 532 and $1064 \mathrm{~nm}$ in order to reduce the divergence of the emitted light. The receiver consists of a 14-inch Schmidt-Cassegrain telescope. The signals collected by the receiver telescope are separated according to wavelength with beam splitters and then transmitted to photomultiplier tubes (PMT). Transient recorders with 12-bit analog-to-digital converters and $250 \mathrm{MHz}$ photon counters are used for processing the output signals of the PMTs. The system allows us to retrieve vertical profiles of the particle backscatter coefficients at 355, 532, and $1064 \mathrm{~nm}$, the particle extinction coefficients at 355 and $532 \mathrm{~nm}$, the linear particle depolarization ratio at $532 \mathrm{~nm}$, the water vapor mixing ratio, and profiles of silicon dioxide (Müller et al., 2010; Tatarov et al., 2011). Profiles of silicon dioxide (quartz) can be used as a proxy of the concentration of mineral dust. In this contribution, we use the signals needed for measuring particle backscatter and extinction coefficients at 355 and $532 \mathrm{~nm}$ and the linear particle depolarization ratio at $532 \mathrm{~nm}$. The measurements were carried out at nighttime under cloud-free conditions.

The profiles of particle backscatter coefficients $\left(\beta_{\mathrm{p}}\right)$ at 355 and $532 \mathrm{~nm}$ were calculated with the Raman method (Ansmann et al., 1992). The overlap effect which describes the incomplete overlap between the outgoing laser beam and the field of view of the receiver telescope is canceled out for the case of profiles of the backscatter coefficient because the ratios of two signals (elastic signals from particles and molecules and the nitrogen Raman signals) are computed (Wandinger and Ansmann, 2002). In that way we can retrieve vertical profiles of the backscatter coefficient to $400 \mathrm{~m}$ above ground. The vertical profiles of the aerosol extinction coefficients $\left(\alpha_{\mathrm{p}}\right)$ at 355 and $532 \mathrm{~nm}$ were derived with the use of the nitrogen vibration Raman signals at 387 and $607 \mathrm{~nm}$ (Ansmann et al., 1990), respectively. The aerosol extinction coefficients can be retrieved above 780 and $540 \mathrm{~m}$ above ground at the measurement wavelengths of 355 and $532 \mathrm{~nm}$, respectively. We derive particle extinction-to-backscatter ratios (lidar ratios, denoted as $S$ in this contribution) at 355 and $532 \mathrm{~nm}$ from the profiles of $\beta_{\mathrm{p}}$ and $\alpha_{\mathrm{p}}$. The lidar ratios can be used for aerosol typing (Müller et al., 2007). Murayama et al. (2004) found values of $S=48.6 \mathrm{sr}$ at $355 \mathrm{~nm}$ and $S=43.1 \mathrm{sr}$ at 532 in a well-isolated Gobi dust-laden layer observed above $4 \mathrm{~km}$ over Tokyo. De Tomasi et al. (2003) reported an $S$ value of less than $50 \mathrm{sr}$ at $351 \mathrm{~nm}$ for a Saharan dust layer. Values of $S$ at $355 \mathrm{~nm}$ ranged between 50 and $80 \mathrm{sr}$ for dust observed over Leipzig, Germany (Mattis et al., 2002). In contrast, Ferrare et al. (2001) reported a high value of $68 \pm 12 \mathrm{sr}$ for the lidar ratio at $355 \mathrm{~nm}$. This high lidar ratio was associated with air masses advected from urban/industrial areas. Omar et al. (2009) founds values of $65-70 \mathrm{sr}$ for the lidar ratio at $532 \mathrm{~nm}$. The numbers describe continental-polluted aerosols and polluted dust.

The backscatter-related Ångström exponent for the wavelength pair of $355 / 532 \mathrm{~nm}$ (denoted as $\AA_{\beta}$ ) is also computed. The backscatter-related Ångström exponent is a good indi- cator of the size of particles. High values $(>1)$ are typically observed for accumulation-mode particles such as fresh biomass-burning particles. Low values $(\sim 0)$ are observed for coarse-mode particles such as Saharan dust or Asian dust (Eck et al., 1999; Sakai et al., 2002; Chen et al., 2007). The values of $0.2-0.3$ are reported as the values of $\AA_{\beta}$ for Saharan dust (Murayama, 2002; Tesche et al., 2009b). Chen et al. (2007) and Müller et al. (2010) found values of 0.7-1.5 for $\AA_{\beta}$ for a mixture of mineral dust with urban haze. Values of $0.8-1.4$ for $\AA_{\beta}$ were found for heavily polluted continental aerosol layers (Franke et al., 2003).

The depolarization ratio is used as an indicator of particle shape (Bohren and Huffman, 1998). High values of the depolarization ratio of 0.3 to 0.35 at $532 \mathrm{~nm}$ indicate nearly pure dust (Sugimoto and Lee, 2006; Freudenthaler et al., 2009). For example, Freudenthaler et al. (2009) reported a value of $\delta_{\mathrm{p}}=0.31$ at $532 \mathrm{~nm}$ for Saharan dust observed during SAMUM 2006. Lidar observations were carried out close to the Taklamakan desert (Iwasaka et al., 2003) and the Gobi desert (Yi et al., 2014). We assume that these dust layers exhibit nearly pure dust conditions as anthropogenic pollution sources in these isolated areas are sparse. Values of $\delta_{\mathrm{p}}$ are in the range of 0.3 to 0.35 at $532 \mathrm{~nm}$ (Iwasaka et al., 2003; Yi et al., 2014). Small values, e.g., values from 0.08 to 0.1 usually are an indicator that dust is mixed with spherical particles (Murayama et al., 2004; Chen et al., 2009; Tesche et al., 2009b; Burton et al., 2013). Anthropogenic aerosols are normally spherical with a small depolarization ratio (Murayama et al., 2003). The degree of depolarization decreases as the sphericity of particles increases. The depolarization ratio is dependent on the mixing ratio of dust with spherical particles. For instance, Burton et al. (2013) reported values of $\delta_{\mathrm{p}}=0.13-0.20$ and $0.03-0.07$ at $532 \mathrm{~nm}$ for polluted dust and urban aerosol particles, respectively.

Parallel polarized and perpendicular polarized signals are measured at $532 \mathrm{~nm}$. The linear volume depolarization ratio (aerosols + molecules) $\delta$ is defined as

$\delta=\frac{P_{\perp}}{P_{\|}+P_{\perp}}$.

$P_{\perp}$ and $P_{\|}$denote the backscatter signal intensities that are polarized perpendicular and parallel with respect to the plane of polarization of the emitted laser beam, respectively. The $\delta$ can be also defined as $P_{\perp} / P_{\|}$(Cairo et al., 1999). We calculated the $\delta$ by using both definitions and compared the difference between the derived values. The results from each individual definition agree within the uncertainty of our depolarization ratio measurements (Tesche et al., 2009a; Shin et al., 2013).

The linear particle depolarization ratio $\delta_{\mathrm{p}}$ differs from $\delta$ as it depends on the concentration of particles in relation to the concentration of air molecules. In this contribution, we use the linear particle depolarization ratio $\left(\delta_{\mathrm{p}}\right)$ according to the 
definition by Shimizu et al. (2004):

$\delta_{\mathrm{p}}=\frac{\delta(z) R_{\mathrm{B}}(z)-\delta_{\mathrm{m}}}{R_{\mathrm{B}}(z)-1}$.

The term $\delta_{\mathrm{m}}$ is the linear depolarization ratio of air molecules at the wavelength of the emitted laser wavelength. We used the value $\delta_{\mathrm{m}}=0.0044$ (Behrendt and Nakamura, 2002). This value takes account of our interference filters, which have a full width at half maximum of $1.0 \mathrm{~nm} . R_{\mathrm{B}}(z)$ is the backscatter ratio, expressed as $\left(\beta_{\mathrm{p}}+\beta_{\mathrm{m}}\right) / \beta_{\mathrm{m}}$ at altitude $z . \beta_{\mathrm{m}}$ denotes the backscatter coefficient of atmospheric molecules. The calibration of the polarization channels was carried out by using rotating polarizers following the methodology explained by Freudenthaler et al. (2009).

\subsection{Dust layer identification}

We use the profiles of the linear particle depolarization ratio for the identification of the Asian dust layers. An example of how the Asian dust layer was determined is shown in Fig. 2. The Asian dust plume reached the Korean peninsula on 22 April 2012. Figure 2 shows the time-height cross section of the range-corrected backscatter signals and the linear volume depolarization ratio at $532 \mathrm{~nm}$. Figure 2 also shows the mean profiles of $\delta$ and $\delta_{\mathrm{p}}, S$ at 355 and $532 \mathrm{~nm}$, and $\AA_{\beta}$ for the measurement from 13:15 to 14:05 UTC.

Values of $\delta_{\mathrm{p}}$ for individual aerosol types are reported in literature; for example, $\delta_{\mathrm{p}}$ for Asian dust particles varies from 0.08 to 0.35 (Murayama et al., 2004; Shimizu et al., 2004; Chen et al., 2009; Shin et al., 2013) at $532 \mathrm{~nm}$. Asian dust generally mixes with pollution during long-range transport which leads to variable $\delta_{\mathrm{p}}$. Thus, this range of $0.08-0.35$ likely describes mixtures of dust with anthropogenic pollution. For instance, Chen et al. (2009) used 0.08 as the threshold value to identify dust in pollution. Furthermore, optical properties may also change during long-range transport. Shimizu et al. (2004) defined 0.1 as the threshold value for the determination of polluted dust. In this study we used 0.08 as the threshold value of $\delta_{\mathrm{p}}$ to identify dust.

In Fig. 2, the layer between 2.7 and $4.6 \mathrm{~km}$ (layer II) contains Asian dust particles as suggested from the values of $\delta_{\mathrm{p}}$, which are higher than 0.16 . The mean value of $\delta_{\mathrm{p}}$ in the layer between 1.2 and $2.5 \mathrm{~km}$ (layer I) is 0.11 and thus also points to the presence of dust particles though the concentration of dust particles compared to the concentration of particles of anthropogenic pollution may be lower in layer I compared to layer II.

Other aerosol optical properties in layer I and layer II differ also. The values of the $S$ in layer I are $64 \pm 4$ and $66 \pm 4 \mathrm{sr}$ at 355 and $532 \mathrm{~nm}$, respectively. The values of the $S$ in layer II are as low $55 \pm 4$ and $55 \pm 3$ sr at 355 and $532 \mathrm{~nm}$, respectively, see Fig. 2d. The standard deviations were computed for the lidar ratios in each of the layers we could identify.
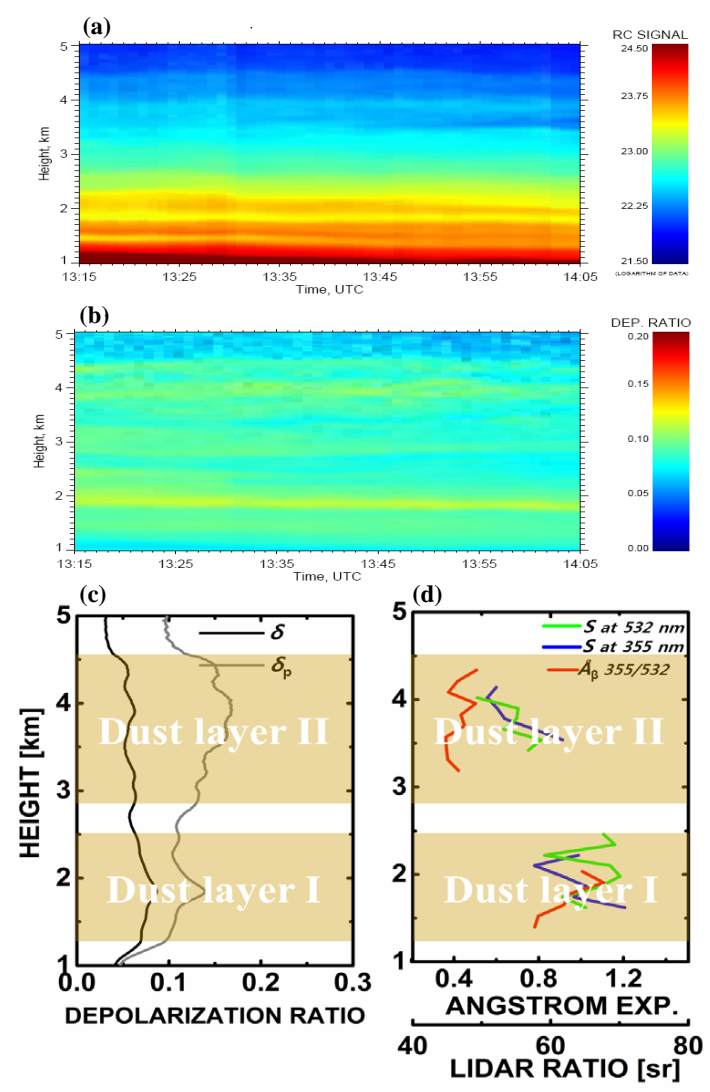

Figure 2. Measurement on 22 April 2012, 13:15-14:05 UTC. Shown are (a) the time-height cross section of the range-corrected signal and (b) the volume depolarization ratio at $532 \mathrm{~nm}$. Also shown are the profiles of (c) the volume depolarization ratio and the linear particle depolarization ratio at $532 \mathrm{~nm}$, and (d) the lidar ratio at 355 and $532 \mathrm{~nm}$ and the backscatter-related Ångström exponents.

The values of $\AA_{\beta}$ in layer I are $\sim 0.93$ and thus considerably higher than in layer II where we find a value of $\sim 0.42$. These numbers suggest that the concentration of small particles is higher in layer I than in layer II, respectively, and that the mean size of particles in layer I is smaller than the mean size of particles in layer II. Regarding the interpretation of the numbers of $\AA_{\beta}$ we need to keep in mind that the backscatterrelated Ångström exponent not only depends on particle size but also on the complex refractive index and particle shape. The same holds true for the values of $S$. The different numbers thus could also result from differences in particle shape and their absorption properties in these mixed Asian dust layers.

\subsection{Analysis of backward trajectories and model simulations of pollution emissions}

We used the HYSPLIT model (Draxler and Rolph, 2003) to generate $120 \mathrm{~h}$ backward trajectories for air parcels arriving above our lidar site. The trajectories describe the different altitude levels in which dust was transported prior to the lidar 
observations. They also allow us to trace back the origin of the dust layers and the transport path.

The Monitoring Atmospheric Composition and Climate (MACC) global air quality service of the European Centre for Medium-Range Weather Forecasts (ECMWF) provides a re-analysis of global atmospheric composition. The reanalysis assimilates satellite data, e.g., total aerosol optical depth (AOD) which is provided by the Moderate Resolution Imaging Spectroradiometer (MODIS), into a global model and data assimilation system to correct for model departures from observational data (Bellouin et al., 2013; Inness et al., 2013). This re-analysis provides fields of aerosols, namely mineral dust, black carbon, organic matter, and sulfate, as well as chemically reactive gases and greenhouse gases. We used the aerosol AOD from the MACC re-analysis to determine the intensity of pollution (AOD) in densely populated and industrialized regions along the transport path of the dust layers and to investigate the influence of anthropogenic pollution particles on the variation of the optical properties of Asian dust.

\section{Results and discussion}

We present data that cover the time from 2009 to 2013. During this time we observed 38 Asian dust layers on 32 days. These Asian dust layers were identified on the basis of the linear particle depolarization ratio measurements as described in Sect. 2.2. The vertical profiles of the linear particle depolarization ratio allow us to determine the vertical distribution of the Asian dust layers.

Figure 3 shows the frequency distribution of $\delta_{\mathrm{p}}, S$, and $\AA_{\beta}$ of Asian dust plumes observed during the observation period. The average value of $\delta_{\mathrm{p}}$ for all observed Asian dust layers is $0.17 \pm 0.02$. The average values of $S$ are $57 \pm 6 \mathrm{sr}$ at $355 \mathrm{~nm}$ and $57 \pm 7 \mathrm{sr}$ at $532 \mathrm{~nm}$. The mean value of $\AA_{\beta}$ is $0.84 \pm 0.37$. The optical properties of each individual Asian dust layer vary over a wide range of values. We find values of $0.08-0.33$ for $\delta_{\mathrm{p}}, 38-83 \mathrm{sr}$ for $S$ at $355 \mathrm{~nm}, 41-73 \mathrm{sr}$ for $S$ at $532 \mathrm{~nm}$, and $0.38-1.71$ for $\AA_{\beta}$. The maximum value of $\delta_{\mathrm{p}}$ is 0.33 at $532 \mathrm{~nm}$. The minimum values of $S$ at $355 \mathrm{~nm}$ and $532 \mathrm{~nm}$ are 38 and $41 \mathrm{sr}$, respectively. The minimum value of $\AA_{\beta}$ is 0.38 . This maximum value of $\delta_{\mathrm{p}}$ and the minimum values of $S$ at 355 and $532 \mathrm{~nm}$, and $\AA_{\beta}$ values are similar to the values of optical properties for pure dust particles. In contrast with these values, low values of $\delta_{\mathrm{p}}$ and high values of $S$ and $\AA_{\beta}$ are also measured. We find that the minimum value of $\delta_{\mathrm{p}}$ is 0.08 at $532 \mathrm{~nm}$. The maximum values of $S$ at 355 and $532 \mathrm{~nm}$ are 83 and $73 \mathrm{sr}$, respectively. The maximum value of $\AA_{\beta}$ is 1.71 . These values are remarkably different from the values of optical properties of pure dust.

We speculate that these differences in the values of the optical properties of dust particles are caused by the effect of long-range transport during which dust mixes with anthro-
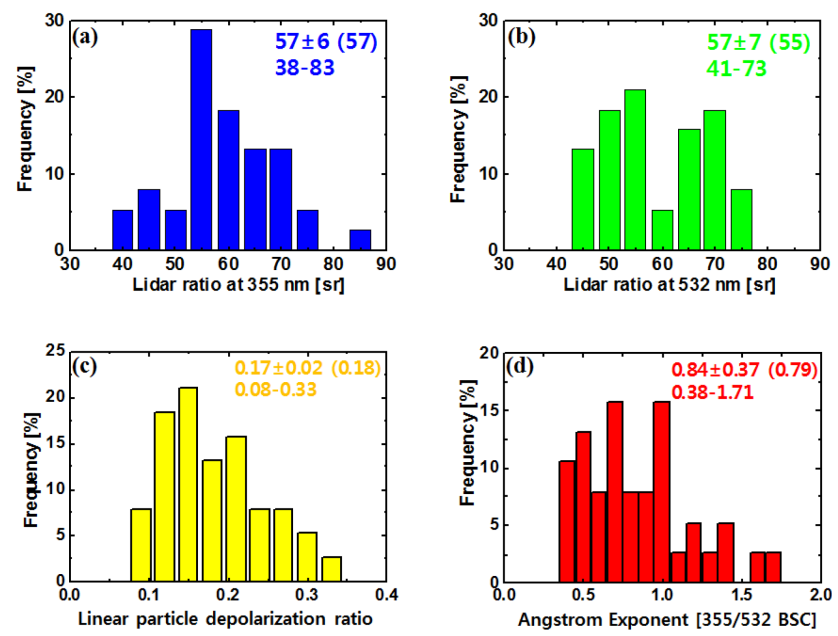

Figure 3. Frequency distributions of optical properties of Asian dust observed between 2009 and 2013. Shown are (a, b) lidar ratios at 355 and $532 \mathrm{~nm}$, (c) linear particle depolarization ratios at $532 \mathrm{~nm}$, and (d) Angström exponents for the wavelength pair $355 / 532 \mathrm{~nm}$. The numbers in each plot indicate the mean value and its standard deviation, the median (shown in brackets), and the minimum and maximum value of each distribution.

pogenic pollution or biomass burning smoke when passing over industrialized/densely populated regions in China.

\subsection{Qualitative analysis of the variation of optical properties of mixed-dust depending on pollution levels}

We divided the dust layers into two episodes. The two episodes differ according to the level of pollution emissions along the transport pathway of the dust plumes. The separation of our measurements into these two episodes was done on the basis of the distribution of aerosol optical depth (AOD) of anthropogenic pollution over China. The Asian dust layers were classified as "more polluted" (MP) Asian dust when the modeled AOD of anthropogenic pollution on that day was higher than the average AOD (modeled) of all 32 observation days considered in this study. In contrast, Asian dust layers that passed over China during episodes of lower AOD, i.e., AOD was below the mean value of modeled AOD of all 32 observation days, are denoted as "less polluted" (LP) Asian dust.

We used model results from MACC and backward trajectory analysis (see Sect. 2.3) for the interpretation of our lidar results as we do not have direct observations of pollution, e.g., particle optical depth, lidar ratios, the linear particle depolarization ratios, or Angström exponents along the transport path of the pollution plumes. The reliability of inferring AOD of pollution from MACC re-analysis is validated by comparing it to results from Aerosol Robotic Network (AERONET) sunphotometer measurements. MACC model 

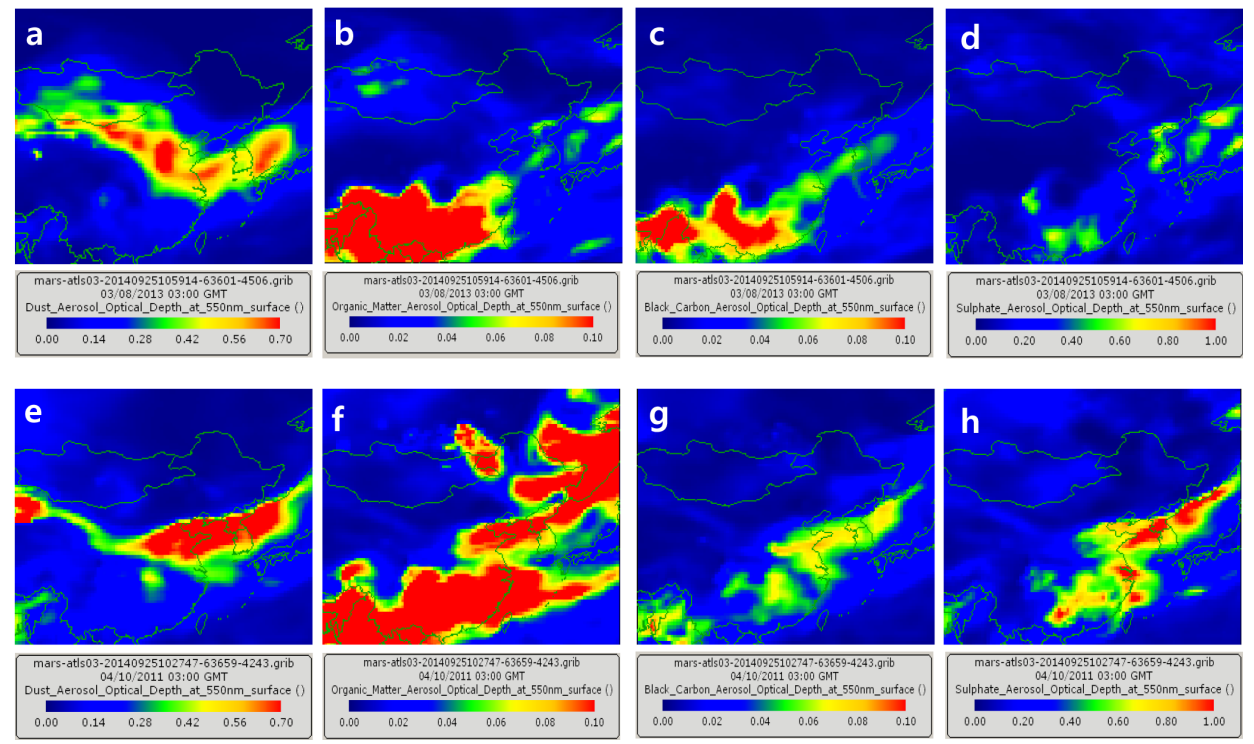

Figure 4. Distribution of AOD at $550 \mathrm{~nm}$ over East Asia retrieved from ECMWF for (a) and (e) dust, (b) and (f) organic matter, (c) and (g) black carbon, and (d) and (h) sulfate aerosol. (a-d) show 8 March 2013. That day is classified as a relatively less polluted day over eastern China. (e-h) show 10 April 2011, which is classified as a comparably more polluted day over eastern China.

is widely used to estimate AOD of pollution (Bellouin et al., 2013; Cesnulyte et al., 2014).

Figure 4 shows the distribution of aerosol optical depth (AOD) at $550 \mathrm{~nm}$ for dust and anthropogenic pollution on 10 April 2010 and 8 March 2013. These pollutants include organic matter, black carbon, and sulfate aerosol. The pollution AOD was computed with the MACC model using re-analysis data of ECMWF. The re-analysis data from the MACC model can be downloaded at the web page of ECMWF (http://apps.ecmwf.int/datasets/data/ macc-reanalysis/). Figure 4 shows that Asian dust particles emitted from the Taklamakan and the Gobi desert were transported across China. The model results of AOD of anthropogenic pollutants over China for 10 April 2010 are significantly higher than the model results of AOD on 8 March 2013.

Figure 5 shows the scatterplot of $\AA_{\beta}$ and $S$ at 355 and $532 \mathrm{~nm}$ vs. $\delta_{\mathrm{p}}$ depending on the transport events denoted as MP and LP. The mean value of $\delta_{\mathrm{p}}$ of the Asian dust layers denoted as LP cases ranges between 0.08 (threshold value that we use to identify dust) and 0.33 . The corresponding values of $\AA_{\beta}$ vary between 0.38 and 1.71 . The lidar ratios range between 38 and $83 \mathrm{sr}$ at $355 \mathrm{~nm}$ and between 41 and $73 \mathrm{sr}$ at $532 \mathrm{~nm}$. The negative correlation of $\delta_{\mathrm{p}}$ with $\AA_{\beta}$ indicates that the impact of the non-spherical particles (Asian dust with high $\delta_{\mathrm{p}}$ ) on the backscattered light decreases with increasing $\AA_{\beta}$. Higher values of $\AA_{\beta}$ indicate a considerable concentration of anthropogenic pollution particles which in turn results in lower values of $\delta_{\mathrm{p}}$, of the mixed dust/pollution plumes.
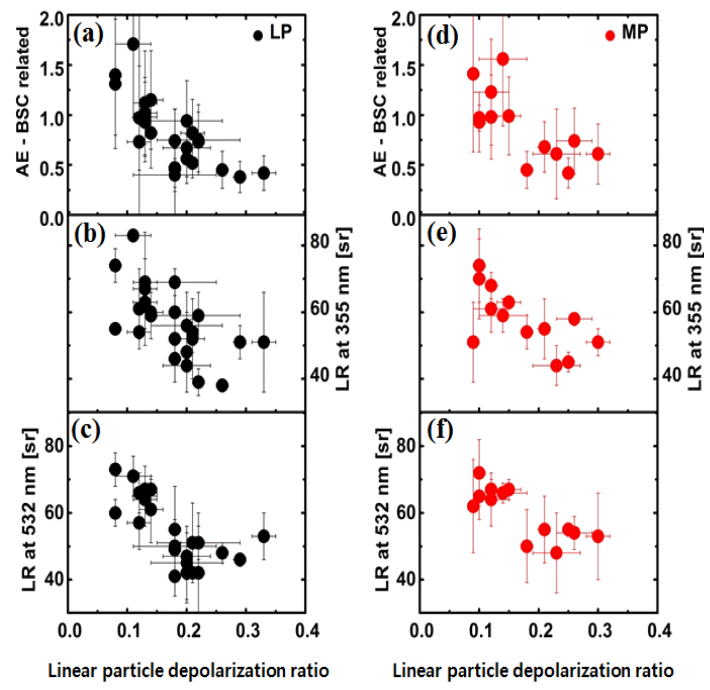

Figure 5. Scatterplot of the linear particle depolarization at $532 \mathrm{~nm}$ versus (a, d) the backscatter-related Ångström exponent $(355 / 532 \mathrm{~nm}$ wavelength pair), (b, e) the lidar ratio at $355 \mathrm{~nm}$ and $(\mathbf{c}, \mathbf{f})$ the lidar ratio at $532 \mathrm{~nm}$. The left column (a-c) shows the optical properties of Asian dust layers considered less polluted (LP), the right column (d-f) shows the more polluted cases.

Lower values of $\delta_{\mathrm{p}}$ are dominantly found in the domain where lidar ratios are above 60-70 sr, except for a few cases. Comparably high lidar ratios are associated with air masses from urban/industrial areas (Noh et al., 2007; Müller et al., 2007; Burton et al., 2012). We find high values of $\delta_{\mathrm{p}}$ for lidar ratios of $57 \pm 7 \mathrm{sr}$ at $355 \mathrm{~nm}$ and $55 \pm 7 \mathrm{sr}$ at $532 \mathrm{~nm}$. 
With regard to the MP cases, the mean $\delta_{\mathrm{p}}$ varies from 0.08 to 0.30 . The corresponding values of $\AA_{\beta}$ vary between 0.42 and 1.56 . The lidar ratios vary between 44 and $74 \mathrm{sr}$ at $355 \mathrm{~nm}$ and between 48 and $72 \mathrm{sr}$ at $532 \mathrm{~nm}$, respectively.

Figure $5 \mathrm{~d}-\mathrm{f}$ shows a negative correlation of $\delta_{\mathrm{p}}$ with $\AA_{\beta}$ and $S$ at 355 and $532 \mathrm{~nm}$. The mean values of the LP and MP cases are summarized in Table 1. The transport pathway of dust over eastern China should influence the degree to which anthropogenic aerosols in the industrial areas contribute to the change of optical properties of dust. However, we do not find significant differences between the LP cases and MP cases. We assume that there is another factor that influences the change of the optical properties of the dust layers we observed.

\subsection{Influence of pathway and vertical distribution of anthropogenic pollution on optical properties of Asian dust}

We classified the Asian dust plumes into two categories with regard to height above ground when they passed over regions of anthropogenic emissions. We used $3 \mathrm{~km}$ height above ground for the classification. The height of $3 \mathrm{~km}$ is reported as the planetary boundary layer. Pollutants emitted at the surface predominantly stay in the planetary boundary layer (Noh et al., 2007; Xie et al., 2015). We assume that height above ground influences how much anthropogenic pollution may mix with the dust layers and thus changes the optical properties of the dust layers. The vertical positions of the dust plumes above ground during transport over China were inferred from the model results. We assume that the height of the dust plumes above ground can be distinguished by HYSPLIT model results although the results may have a certain error because of the spatial and temporal complexity of the meteorological fields involved in the computations.

Figure 6 shows the transport pathway and the change of the vertical position of the dust plumes during transport to our lidar site. It is clear that backward trajectories cannot provide us with information on the concentration of dust and anthropogenic pollution in the air masses prior to observation over the Korean peninsula. Still, backward trajectories show if the air masses originated from the desert regions or nearby, and whether the air masses passed over densely populated/industrialized regions.

Case I includes those Asian dust plumes that passed over industrialized areas in China at high altitude levels $(>3 \mathrm{~km}$ height above ground) as shown in Fig. 6a. The Asian dust plumes were classified as case II when they were transported through the near surface/lower troposphere $(<3 \mathrm{~km}$ height above ground) over industrialized areas in China, i.e., longitude between 110 and $125^{\circ} \mathrm{E}$; the locations of industrialized and densely populated regions in China are shown in Fig. 1.

The mean values of the linear particle depolarization ratios of the Asian dust plumes we observed are lower compared to the linear particle depolarization ratios of pure dust particles.
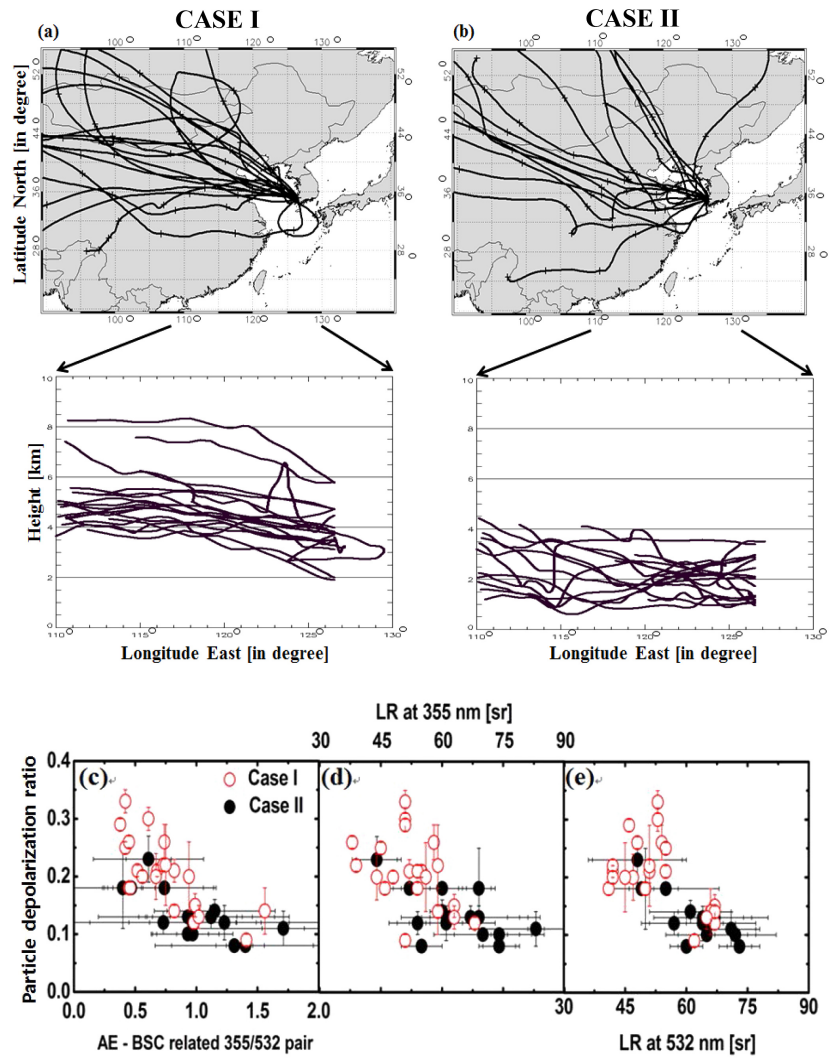

Figure 6. Top panels: transport pattern of the dust plumes that originated in the desert regions and passed over industrialized/populated regions of China before arrival over the Korean peninsula. Middle panels: vertical position of the dust layers during transport: (a) dust layers passed over China at high altitude (case I) (b) dust layers were transported over China through the near surface/lower troposphere (case II). Bottom panels: scatterplot of the linear particle depolarization at $532 \mathrm{~nm}$ versus (c) the backscatter-related Ångström exponent (355/532 $\mathrm{nm}$ wavelength pair), and the (d, e) lidar ratio (at $355 \mathrm{~nm}$ and at $532 \mathrm{~nm}$ ) with respect to case I and case II. The two categories I and II are denoted by different colors. case I is indicated by red circles. case II is indicated by black circles.

For example, Freudenthaler et al. (2009) reported a value of $\delta_{\mathrm{p}}=0.31$ at $532 \mathrm{~nm}$ for pure Saharan dust observed during SAMUM 2006.

The values of $\delta_{\mathrm{p}}$ and the corresponding values of $\AA_{\beta}$ and $S$ at 355 and $532 \mathrm{~nm}$ for the cases I and II are also shown in Fig. 6 . The corresponding mean values of the parameters of these two cases are also summarized in Table 1.

We find different clusters of the optical properties of the dust layers when we take into consideration their vertical position during transport. Case I shows larger values of $\delta_{\mathrm{p}}$ compared to the depolarization ratios in case II. On average, $\AA_{\beta}$ of case I is smaller than $\AA_{\beta}$ of case II. The average values of $\delta_{\mathrm{p}}$ and $\AA_{\beta}$ are $0.21 \pm 0.06$ and $0.74 \pm 0.31$, respectively, for case I. In contrast, $\delta_{\mathrm{p}}$ and $\AA_{\beta}$ are $0.13 \pm 0.04$ and $0.98 \pm 0.35$, respectively, for case II. The lowest values of $S$ at 355 and 
Table 1. Summary of the linear particle depolarization ratio at $532 \mathrm{~nm}$, lidar ratios, and backscatter-related Ångström exponents of Asian dust layers for each classification. Asian dust layers were classified according to a levels of anthropogenic pollution emissions: LP denotes that Asian dust layers which are considered less polluted and MP denotes that Asian dust layers which are considered more polluted; ${ }^{b}$ their vertical position in a polluted region: case I indicates Asian dust layers passed over China at high altitude ( $>3 \mathrm{~km})$ before they arrived over Gwangju, and case II indicates Asian dust layers were transported at low altitude $(<3 \mathrm{~km})$ over industrialized areas before they arrived over Gwangju; and ${ }^{\mathrm{c}}$ their vertical position (below $3 \mathrm{~km}$ or above $3 \mathrm{~km}$ ) and level of pollution (LP or MP) when they passed over China.

\begin{tabular}{|c|c|c|c|c|c|c|}
\hline & & \multirow{2}{*}{$\begin{array}{c}\text { Number of } \\
\text { observed layers }\end{array}$} & \multirow[b]{2}{*}{$\delta_{\mathrm{p}}$} & \multicolumn{2}{|c|}{$S[\mathrm{sr}]$} & \multirow[b]{2}{*}{$\AA_{\beta}$} \\
\hline \multicolumn{2}{|c|}{ Classification } & & & $355 \mathrm{~nm}$ & $532 \mathrm{~nm}$ & \\
\hline \multirow[t]{2}{*}{ Pollution level $^{\mathrm{a}}$} & LP & 25 & $0.17 \pm 0.02$ & $57 \pm 7$ & $55 \pm 7$ & $0.82 \pm 0.37$ \\
\hline & MP & 13 & $0.17 \pm 0.02$ & $58 \pm 6$ & $59 \pm 8$ & $0.89 \pm 0.38$ \\
\hline \multirow[t]{2}{*}{ Vertical position ${ }^{\mathrm{b}}$} & case I & 16 & $0.21 \pm 0.06$ & $52 \pm 7$ & $53 \pm 8$ & $0.74 \pm 0.31$ \\
\hline & case II & 22 & $0.13 \pm 0.04$ & $63 \pm 9$ & $62 \pm 8$ & $0.98 \pm 0.35$ \\
\hline Pollution level \& & LP_below $3 \mathrm{~km}$ & 12 & $0.13 \pm 0.03$ & $64 \pm 9$ & $62 \pm 8$ & $1.00 \pm 0.38$ \\
\hline \multirow[t]{3}{*}{ Vertical position ${ }^{\mathrm{c}}$} & LP_above $3 \mathrm{~km}$ & 13 & $0.21 \pm 0.05$ & $51 \pm 8$ & $49 \pm 9$ & $0.65 \pm 0.20$ \\
\hline & MP_below $3 \mathrm{~km}$ & 8 & $0.13 \pm 0.04$ & $61 \pm 10$ & $64 \pm 7$ & $1.09 \pm 0.30$ \\
\hline & MP_above $3 \mathrm{~km}$ & 5 & $0.24 \pm 0.05$ & $53 \pm 5$ & $53 \pm 2$ & $0.58 \pm 0.14$ \\
\hline
\end{tabular}

$532 \mathrm{~nm}$ are also measured for high values of $\delta_{\mathrm{p}}(0.21 \pm 0.06)$. We find values of $52 \pm 7 \mathrm{sr}$ at $355 \mathrm{~nm}$ and $53 \pm 8 \mathrm{sr}$ at $532 \mathrm{~nm}$, respectively, for case I. Comparably high values of $S$ were found for case II, i.e., $63 \pm 9 \mathrm{sr}$ at $355 \mathrm{~nm}$ and $62 \pm 8 \mathrm{sr}$ at $532 \mathrm{~nm}$. In that case the value of $\delta_{\mathrm{p}}$ is $0.13 \pm 0.04$.

There are several previous studies that report on linear particle depolarization ratios of polluted dust after long-range transport. According to these studies the observed dust particles were partly/completely mixed with anthropogenic pollution (Sakai et al., 2002; Müller et al., 2003; Shimizu et al., 2004; Chen et al., 2007). As a result of the mixing of dust with anthropogenic pollution, the values of $\delta_{\mathrm{p}}$ were lower than the values of pure dust, which are estimated to be in the range of 0.3-0.35 (Murayama et al., 2004; Freudenthaler et al., 2009). Likewise, the values of $\AA_{\beta}$ and $S$ also differ compared to the values of $\AA_{\beta}$ and $S$ of pure dust.

We assume that the dust particles carried more anthropogenic pollution in the cases where the air masses traveled near the surface. Consequently, the optical characteristics of the dust/pollution layers of case II are dominated by the optical properties of anthropogenic pollutants. In contrast, the optical properties of dust layers that traveled at high altitudes (case I) are less influenced by urban/industrial pollutants. Thus, the optical properties of these dust layers are more likely to be those of pure dust.

The Asian dust plumes were classified into four categories. We considered not only the level of pollution emissions along the transport pathway, i.e., MP Asian dust and LP Asian dust, but also the vertical position of the layers when they passed over polluted regions of China (below $3 \mathrm{~km}$ and above $3 \mathrm{~km}$ ). Figure 7 shows scatterplot of $\AA_{\beta}$ (wavelength range $355 / 532 \mathrm{~nm}$ ), and $S$ at 355 and $532 \mathrm{~nm}$ versus $\delta_{\mathrm{p}}$ at $532 \mathrm{~nm}$ depending on the level of pollution emission and the vertical position. The corresponding mean values of the optical parameters of those clusters are given in Table 1 . We expect that the optical properties of Asian dust change most if pollution levels (in terms of AOD) are high, (MP Asian case) and when the corresponding air masses pass over industrialized area of China at low altitude (below $3 \mathrm{~km}$ height above ground). The mean values of $\delta_{\mathrm{p}}$ at $532 \mathrm{~nm}$ and $\AA_{\beta}$ are $0.13 \pm 0.04$ and $1.09 \pm 0.30$, respectively, for this case which is denoted as MP_below $3 \mathrm{~km}$. The mean values of $S$ are $61 \pm 10 \mathrm{sr}$ at $355 \mathrm{~nm}$ and $64 \pm 7 \mathrm{sr}$ at $532 \mathrm{~nm}$. However, these values of optical properties of dust for MP_below $3 \mathrm{~km}$ are not significantly different from the case of LP_below $3 \mathrm{~km}$. In that case the mean values of $\delta_{\mathrm{p}}$ at $532 \mathrm{~nm}$ and $\AA_{\beta}$ are $0.13 \pm 0.03$ and $1.00 \pm 0.38$, respectively. The mean values of $S$ are $64 \pm 9 \mathrm{sr}$ at $355 \mathrm{~nm}$ and $62 \pm 8 \mathrm{sr}$ at $532 \mathrm{~nm}$.

The difference in values of optical properties between MP and LP at high altitude also do not differ significantly. The mean values of $\delta_{\mathrm{p}}$ at $532 \mathrm{~nm}, \AA_{\beta}$, and $S$ are $0.24 \pm 0.05$, $0.58 \pm 0.14$, and $53 \pm 5 \mathrm{sr}$ at $355 \mathrm{~nm}$ and $53 \pm 2 \mathrm{sr}$ at $532 \mathrm{~nm}$, respectively, for the case MP_above $3 \mathrm{~km}$. The highest values of $\delta_{\mathrm{p}}$ and lowest values of $\AA_{\beta}$ are found for this case.

In the case of LP_above $3 \mathrm{~km}$, the mean values of $\delta_{\mathrm{p}}$ at $532 \mathrm{~nm}$ and $\AA_{\beta}$ are $0.21 \pm 0.05$ and $0.65 \pm 0.20$, respectively. The mean values of $S$ are $51 \pm 8 \mathrm{sr}$ at $355 \mathrm{~nm}$ and $49 \pm 9 \mathrm{sr}$, respectively. We believe that the changes in the optical properties of Asian dust depend on the vertical position of the dust plume rather than the level of pollution emission during transport.

The clusters denoted as case I and case II were classified according to the altitude (above ground) at which the dust-laden air masses passed over industrialized/populated regions of China. The differences in the optical properties of the dust layers are shown in Fig. 8. The corresponding values 
Table 2. Linear particle depolarization ratio at $532 \mathrm{~nm}$, lidar ratios, and backscatter-related Ångström exponents of East Asian dust layers according to the altitude range in which these plumes passed over polluted regions of China. Case I describes the layer from 3 to 4 and above $4 \mathrm{~km}$. Case II describes the layers from 0 to 1,1 to 2 , and 2 to $3 \mathrm{~km}$ height above ground.

\begin{tabular}{llccccc}
\hline & & & \multicolumn{2}{c}{$S[\mathrm{sr}]$} & \\
\cline { 5 - 6 } $\begin{array}{c}\text { Height of dust layer at } \\
\text { pollution regions }\end{array}$ & $\begin{array}{c}\text { Number of } \\
\text { observed layers }\end{array}$ & $\delta_{\mathrm{p}}$ & $355 \mathrm{~nm}$ & $532 \mathrm{~nm}$ & $\AA_{\beta}$ \\
\hline Case I & Above $4 \mathrm{~km}$ & 14 & $0.23 \pm 0.02$ & $50 \pm 7$ & $49 \pm 8$ & $0.60 \pm 0.27$ \\
& $3-4 \mathrm{~km}$ & 1 & $0.20 \pm 0.04$ & $44 \pm 2$ & $47 \pm 7$ & $0.67 \pm 0.29$ \\
\hline Case II & $2-3 \mathrm{~km}$ & 7 & $0.13 \pm 0.02$ & $61 \pm 7$ & $66 \pm 5$ & $1.11 \pm 0.47$ \\
& $1-2 \mathrm{~km}$ & 6 & $0.15 \pm 0.03$ & $65 \pm 7$ & $59 \pm 9$ & $0.94 \pm 0.42$ \\
& Below $1 \mathrm{~km}$ & 10 & $0.12 \pm 0.01$ & $63 \pm 7$ & $64 \pm 6$ & $1.00 \pm 0.43$ \\
\hline
\end{tabular}

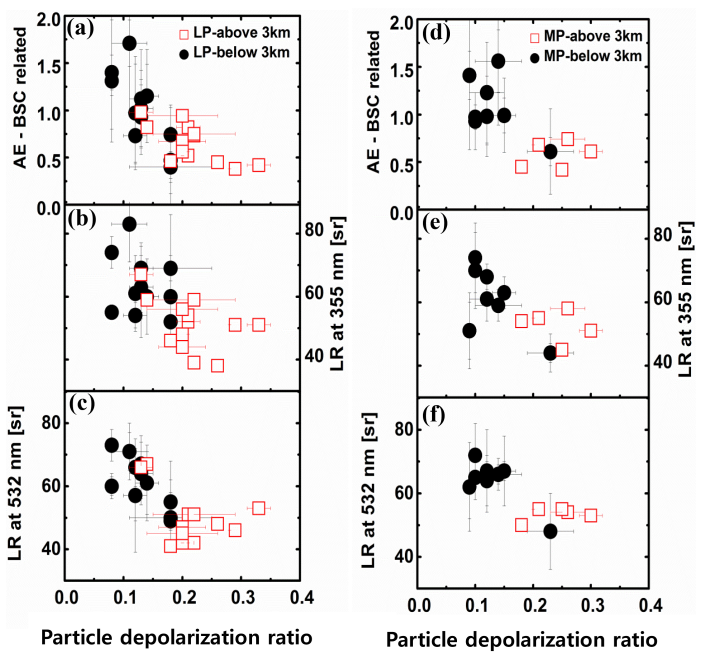

Figure 7. Scatterplot of the linear particle depolarization at $532 \mathrm{~nm}$ versus $(\mathbf{a}, \mathbf{d})$ the backscatter-related Ångström exponent (355/532 nm wavelength pair), (b, e) the lidar ratio at $355 \mathrm{~nm}$ and $(\mathbf{c}, \mathbf{f})$ the lidar ratio at $532 \mathrm{~nm}$. The left column (a-c) shows the optical properties of Asian dust layers considered less polluted (LP), the right column (d-f) shows the more polluted cases. The Asian dust layers that passed over polluted regions in China at low altitude are denoted by black circles. The Asian dust layers transported at high altitude are denoted by red squares.

of the optical characteristics of the Asian dust layers at each individual height are summarized in Table 2. The difference of the optical characteristics of East Asian dust layers that traveled in near-surface heights and at high altitudes is obvious. The values of $\delta_{\mathrm{p}}, \AA_{\beta}$, and $S$ are $0.12 \pm 0.01,1.00 \pm 0.43$, and $63 \pm 7 \mathrm{sr}$ at $355 \mathrm{~nm}$ and $64 \pm 6 \mathrm{sr}$ at $532 \mathrm{~nm}$, respectively, when Asian dust passed over China below $1 \mathrm{~km}$ height above ground. These values reflect the fact that the optical properties of the dust/pollution plumes are dominated by the anthropogenic part of the particles in these plumes. Lower values of $\delta_{\mathrm{p}}$ represent the dominance of spherical particles, i.e., the presence of urban pollution. High values of $\AA_{\beta}$ indicate that small particles dominate in the lower altitude level. The high lidar ratio also indicates the presence of urban pollution which tends to be more light absorbing (Müller et al., 2007). In contrast, values for $\delta_{\mathrm{p}}, \AA_{\beta}$, and $S$ are $0.23 \pm 0.04$, $0.60 \pm 0.17$, and $50 \pm 6 \mathrm{sr}$ at $355 \mathrm{~nm}$ and $49 \pm 5 \mathrm{sr}$ at $532 \mathrm{~nm}$, respectively, after the dust layers had passed over China at high altitudes (above $3 \mathrm{~km}$ ). These values more likely reflect the optical characteristic of Asian dust particles that are less affected by the contribution of anthropogenic pollution. The optical properties of Asian dust layer observed in our study reflect mixtures between different aerosol types.

We notice that these variations of the optical properties of Asian dust layers may not only be the result of external mixing. Hygroscopic growth, aging and deposition during transport, and internal mixing might also affect dust properties (Burton et al., 2014). Interpretation of the mixing state of Asian dust is a challenging task. The mixing state depends on many variables which are poorly known. Sugimoto et al. (2015) tried to identify the mixing state of Asian dust (internal mixing or external mixing) by using analytical relationships inferred from lidar observations. However, we will not go into details here. We assume that most of the Asian dust observed in this study was externally mixed.

The altitude in which the Asian dust layers passed over China have significant influence on their optical characteristics. In our study, we took $3 \mathrm{~km}$ above ground as the threshold value as we observed a notable change of optical properties of the dust/pollution plumes if they traveled above or below $3 \mathrm{~km}$ height above ground. Pollution particles below $3 \mathrm{~km}$ could mix and interact with Asian dust particles (more influence). In contrast, we assume that optical properties of dust particles above $3 \mathrm{~km}$ are not that influenced by anthropogenic pollution as the mixing of pollution into these heights is less intense.

We emphasize that this threshold value of $3 \mathrm{~km}$ is merely a best estimate which is governed by the set of data we have at hand. We lack additional information that would allow us to refine our data analysis. For example, a longer time series of lidar measurements, (vertically resolved) observations of pollution transported over China, measurements under much 


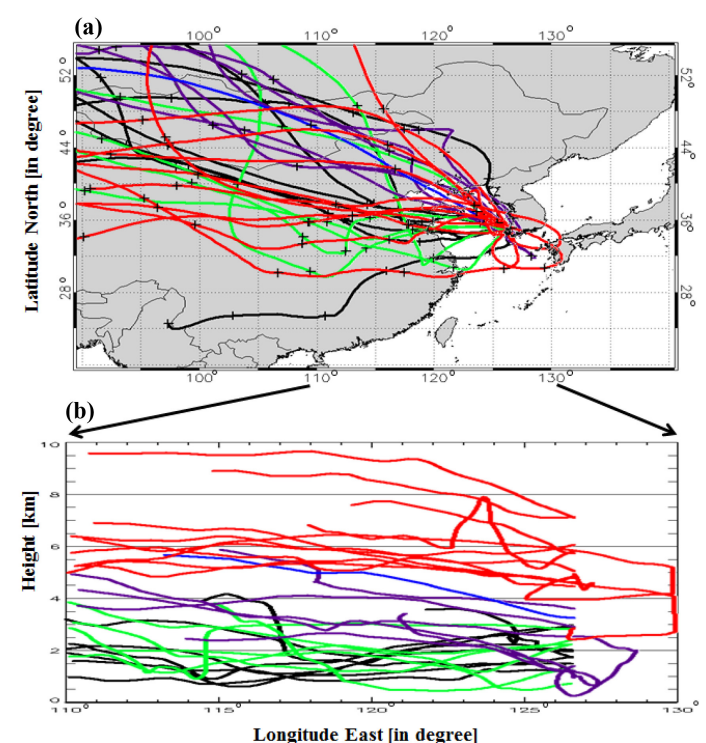

(c)

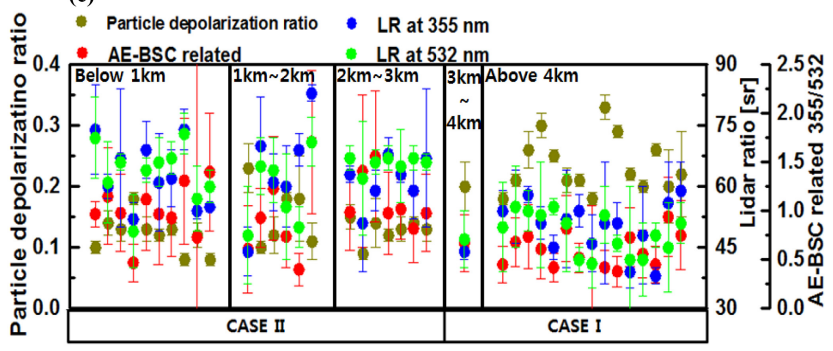

Figure 8. (top panel) (a) transport path and classification of East Asian dust layers with respect to (b) their altitude above ground when they passed over industrial regions of China. Bottom panel: transport path and corresponding altitude of Asian dust layers are distinguished by color (black: 0-1 km; green: 1-2 km; purple: $2-$ $3 \mathrm{~km}$; blue: $3-4 \mathrm{~km}$; red: above $4 \mathrm{~km}$ ). Scatterplots of the linear particle depolarization at $532 \mathrm{~nm}$ (dark yellow), the backscatter-related Ångström exponent (355/532 nm wavelength pair, red), the lidar ratio at $355 \mathrm{~nm}$ (blue), the lidar ratio at $532 \mathrm{~nm}$ (green) depending on the five altitude categories (c). The height of the Asian dust layers above ground is separated by vertical lines. Case I included the layers from 3 to $4 \mathrm{~km}$ and above $4 \mathrm{~km}$. Case II includes the layers from 0 to 1,1 to 2 , and 2 to $3 \mathrm{~km}$ height above ground.

more variable meteorological conditions, additional modeling results, just to name a few causes, might change this threshold value.

We also investigated the optical properties of Asian dust with respect to transport time at different height levels. Figure 9 shows scatterplots of optical properties of Asian dust versus the transport time. The correlation study is based on HYSPLIT model results, our profiles of $\delta_{\mathrm{p}}, \AA_{\beta}$, and $S$, and the time (in hours) the Asian dust spent in polluted regions over China during the transport. We can only use HYSPLIT results as an estimate of the total transport time and the time the plumes spent over pollution regions of China. The total transport time may have considerable uncertainty. We need
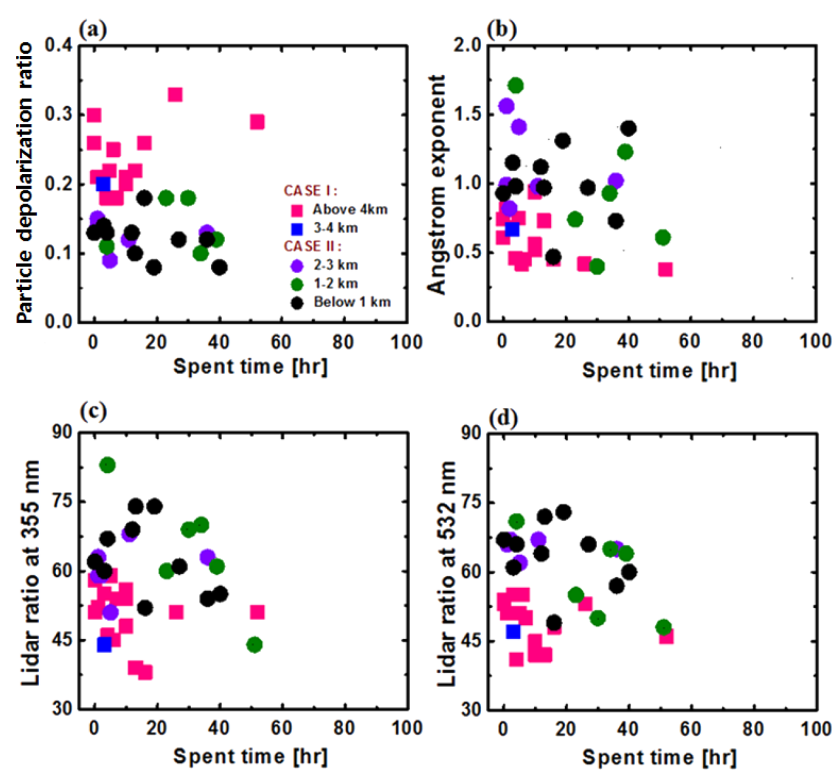

Figure 9. Scatterplot of optical dust properties versus the time the Asian dust layers traveled over polluted regions in China. Shown are (a) the particle depolarization ratio, (b) the backscatter-related Ångström exponent (355/532 nm wavelength pair), (c) the lidar ratio at $355 \mathrm{~nm}$, and (d) the lidar ratio at $532 \mathrm{~nm}$ with respect to their altitude above ground when they passed over industrial regions of China. The corresponding altitude of Asian dust layers is distinguished by color (black: below $0 \mathrm{~km}$; green: $1-2 \mathrm{~km}$; purple: 2 $3 \mathrm{~km}$; blue: $3-4 \mathrm{~km}$; red: above $4 \mathrm{~km}$ ).

to decide from the trajectories the starting point of dust emission, and this means we take the time when the air parcel (defined by its trajectory) left one of the desert regions in Central Asia. The height above ground during transport and the time the plumes spent over pollution regions also contains uncertainty as we neither have direct measurements of the height distribution of the plumes over China during transport nor do we have information on the pollution levels over China while the desert plumes traveled over China at the various height layers. We can merely assume that the likelihood of mixing with dust and pollution increases the lower the dust travels above ground and the longer it travels at low heights.

We again used our classification of case I and case II. However, we refined the vertical resolution to five height layers: transport occurred below 1, from 1 to 2,2 to 3,3 to 4 , and above $4 \mathrm{~km}$. We wanted to test if a more refined height separation would give us more insight into the change of optical properties with transport time and transport height.

The absolute time the dust layers spent in these different height levels is presented in Fig. 9. We also tested the effect of relative time in relation to total transport time but could not find a clear pattern. We find a maximum value of 0.3 for $\delta_{\mathrm{p}}$ at $532 \mathrm{~nm}$. On average, the depolarization decreases with increasing residence time over China. However, this dependence differs with respect to the height above ground of dust 
layers. The change of the depolarization ratio of dust layers traveling above $3 \mathrm{~km}$ above ground seems less dependent on the residence time over a given area.

We believe that short residence times (fast transport to the Korea peninsula, $20 \mathrm{~h}$ or less) reduces the chances that pollution may mix with dust, particularly if dust traveled below $3 \mathrm{~km}$ above ground. In contrast, longer residence times (slow transport to the Korea peninsula, $>50 \mathrm{~h}$ ) of the dust plumes may have increased the chances that pollution mixed with dust if dust traveled below $3 \mathrm{~km}$ height above ground.

Regarding $\AA_{\beta}$ we find a maximum value of 1.75 which decreases to 0.5 for slow transport of the plumes. The decrease of $\AA_{\beta}$ with transport time seems to be correlated for plumes that mainly stay below $3 \mathrm{~km}$ height above ground. In contrast, if plumes were above $3 \mathrm{~km}, \AA_{\beta}$ does not seem to change with transport time. In that case, the mixing of pollution with dust may have been less likely because of the fast transport.

With regard to $S$ at 355 and $532 \mathrm{~nm}$, we find a maximum value of approximately $75 \mathrm{sr}$ which drops to approximately $40 \mathrm{sr}$ for slow transport. Again, we see that for plumes below $3 \mathrm{~km}$ height above ground, transport time seems to matter. $S$ drops with increasing transport time. For the case of plumes above $3 \mathrm{~km}$, i.e., dust that likely is not too affected by mixing with anthropogenic pollution, the lidar ratios do not seem to depend on transport time. This result may however again be caused by the fact that transport times to the Korea peninsula are comparably short.

We further investigated these results. We initially assumed that $\AA_{\beta}$ either should increase with transport time or does not drop significantly for pollution that travels near the ground as there should be a higher share of small anthropogenic pollution particles in the dust plume (large particles). This opposite behavior may be caused by the state of mixing, i.e., pollution particles attach to the dust particles, thus increasing their mean size. Hygroscopic growth of particles attached to dust may further contribute to the increase of mean size. One point that complicates this interpretation is that $\AA_{\beta}$ does not only depend on particle size but also on particle shape and the real and imaginary part (scattering and absorption) of the particles.

With regard to $S$, we also expected that $S$ would increase with increasing transport times. If the particles travel at low height above ground, more anthropogenic pollution should mix with dust. The decrease of $S$ however suggests an increase of particle size and a decrease of the light-absorption capacity. Hygroscopic particle growth, i.e., the increase of mean particle size and decrease of light absorption by uptake of water, might be responsible for this behavior.

We stress that other reasons may be responsible for these results. We have a comparably small set of observations. We have insufficient information whether the plumes consisted of internal and/or external mixtures. The shape and size of particles of mixed Asian dust might be influenced in a much more significant way by transport time. The kind of mixing between the dust particles and pollution particles could influence the light-absorption properties.

\section{Summary and conclusion}

In this study we presented the differences in optical properties of mixed Asian dust layers depending on their vertical position over China during transport from the Chinese dust source regions to the Korea peninsula, downwind of the source regions. The data cover the time frame from 2009 to 2013. The dust layers are divided into several categories which can be characterized by different heights above ground during transport. The change of height above ground during transport of the dust layers was identified by backward trajectory analysis.

The optical properties of Asian dust significantly change depending on the dust plumes, the vertical position, and the change of vertical position above ground level during transport over China. We find lower values for the lidar ratios at 355 and $532 \mathrm{~nm}$, lower backscatter-related Ångström exponents (wavelength pair 355/532 nm), and higher linear particle depolarization ratios at $532 \mathrm{~nm}$ for Asian dust that was transported at high altitudes ( $>3 \mathrm{~km}$ height above ground) compared to the situation in which the dust plumes moved at low altitudes across China. The mean linear particle depolarization ratio is $0.21 \pm 0.06$ for transport at high altitudes. The mean lidar ratios in that case are $52 \pm 7$ and $53 \pm 8$ sr at 355 and $532 \mathrm{~nm}$, respectively. The mean Ångström exponent is $0.74 \pm 0.31$. These values likely reflect properties of dust little affected by anthropogenic pollution. However, we cannot quantify the amount of anthropogenic pollution that may still be present in these dust layers. In contrast, higher values for the lidar ratios and the backscatter-related Angström exponents, and lower values of the linear particle depolarization, were found for dust layers that crossed highly polluted regions in China at low altitudes. The value of the mean linear particle depolarization ratio is $0.13 \pm 0.04$. The mean lidar ratios are $63 \pm 9$ and $62 \pm 8 \mathrm{sr}$ at 355 and $532 \mathrm{~nm}$, respectively. The mean backscatter-related Angström exponent is $0.98 \pm 0.35$. These values more likely describe strong influence by anthropogenic pollution; i.e., that the uptake of urban pollution by dust may have been significant.

Our results suggest that the transport pathway as well as the vertical position of Asian dust during long-range transport may have significant impact on the optical properties of mixed Asian dust layers. 
Acknowledgements. This work was supported by a National Research Foundation of Korea (NRF) grant funded by the Korean government (MEST) (no. 2012R1A1A2002983) as well as the Korea Meteorological Administration Research and Development Program under grant KMIPA2015-2012. This research was also supported by International Environmental Research Center (IERC).

Edited by: M. Tesche

\section{References}

Ansmann, A., Riebesell, M., and Weitkamp, C.: Measurement of atmospheric aerosol extinction profiles with a Raman lidar, Opt. Lett., 15, 746-748, 1990.

Ansmann, A., Wandinger, U., Riebesell, M., Weitkamp, C., and Michaelis, W.: Independent measurement of extinction and backscatter profiles in cirrus clouds by using a combined Raman elastic-backscatter lidar, Appl. Optics, 31, 7113-7131, 1992.

Behrendt, A. and Nakamura, T.: Calculation of the calibration constant of polarization lidar and its dependency on atmospheric temperature, Opt. Express, 10, 805-817, 2002.

Bellouin, N., Quaas, J., Morcrette, J.-J., and Boucher, O.: Estimates of aerosol radiative forcing from the MACC re-analysis, Atmos. Chem. Phys., 13, 2045-2062, doi:10.5194/acp-13-20452013, 2013.

Bohren, C. F. and Huffman, D. R.: Absorption and Scattering by a Sphere, in: Absorption and Scattering of Light by Small Particles, Wiley-VCH Verlag GmbH, Weinheim, Germany, doi:10.1002/9783527618156.ch4, 1998.

Burton, S. P., Ferrare, R. A., Hostetler, C. A., Hair, J. W., Rogers, R. R., Obland, M. D., Butler, C. F., Cook, A. L., Harper, D. B., and Froyd, K. D.: Aerosol classification using airborne High Spectral Resolution Lidar measurements - methodology and examples, Atmos. Meas. Tech., 5, 73-98, doi:10.5194/amt-5-73-2012, 2012.

Burton, S. P., Ferrare, R. A., Vaughan, M. A., Omar, A. H., Rogers, R. R., Hostetler, C. A., and Hair, J. W.: Aerosol classification from airborne HSRL and comparisons with the CALIPSO vertical feature mask, Atmos. Meas. Tech., 6, 13971412, doi:10.5194/amt-6-1397-2013, 2013.

Burton, S. P., Vaughan, M. A., Ferrare, R. A., and Hostetler, C. A.: Separating mixtures of aerosol types in airborne High Spectral Resolution Lidar data, Atmos. Meas. Tech., 7, 419-436, doi:10.5194/amt-7-419-2014, 2014.

Cairo, F., Di Donfrancesco, G., Adriani, A., Pulvirenti, L., and Fierli, F.: Comparison of various linear depolarization parameters measured by lidar, Appl. Optics, 38, 4425-4432, 1999.

Carrico, C. M., Kus, P., Rood, M. J., Quinn, P. K., and Bates, T. S.: Mixtures of pollution, dust, sea salt, and volcanic aerosol during ACE-Asia: radiative properties as a function of relative humidity, J. Geophys. Res.-Atmos., 108, 8650, doi:10.1029/2003JD003405, 2003.

Cesnulyte, V., Lindfors, A. V., Pitkänen, M. R. A., Lehtinen, K. E. J., Morcrette, J.-J., and Arola, A.: Comparing ECMWF AOD with AERONET observations at visible and UV wavelengths, Atmos. Chem. Phys., 14, 593-608, doi:10.5194/acp-14593-2014, 2014.
Chen, W.-N., Tsai, F.-J., Chou, C. C.-K., Chang, S.-Y., Chen, Y.W., and Chen, J.-P.: Optical properties of Asian dusts in the free atmosphere measured by Raman lidar at Taipei, Taiwan, Atmos. Environ., 41, 7698-7714, 2007.

Chen, W.-N., Chen, Y.-W., Chou, C. C., Chang, S.-Y., Lin, P.H., and Chen, J.-P.: Columnar optical properties of tropospheric aerosol by combined lidar and sunphotometer measurements at Taipei, Taiwan, Atmos. Environ., 43, 2700-2708, 2009.

De Tomasi, F., Blanco, A., and Perrone, M. R.: Raman lidar monitoring of extinction and backscattering of African dust layers and dust characterization, Appl. Optics, 42, 1699-1709, 2003.

Draxler, R. R. and Rolph, G.: HYSPLIT (Hybrid Single-Particle Lagrangian Integrated Trajectory) model access via NOAA ARL READY website, NOAA Air Resources Laboratory, Silver Spring, MD, available at: http://www.arl.noaa.gov/ready/ hysplit4.html (last access: October 2014), 2003.

Durant, A. J., Harrison, S. P., Watson, I. M., and Balkanski, Y.: Sensitivity of direct radiative forcing by mineral dust to particle characteristics, Prog. Phys. Geog., 33, 80-102, 2009.

Eck, T., Holben, B., Reid, J., Dubovik, O., Smirnov, A., O’neill, N., Slutsker, I., and Kinne, S.: Wavelength dependence of the optical depth of biomass burning, urban, and desert dust aerosols, J. Geophys. Res.-Atmos., 104, 31333-31349, 1999.

Ferrare, R. A., Turner, D. D., Brasseur, L. H., Feltz, W. F., Dubovik, O., and Tooman, T. P.: Raman lidar measurements of the aerosol extinction-to-backscatter ratio over the Southern Great Plains, J. Geophys. Res.-Atmos., 106, 20333-20347, doi:10.1029/2000JD000144, 2001.

Franke, K., Ansmann, A., Müller, D., Althausen, D., Venkataraman, C., Reddy, M. S., Wagner, F., and Scheele, R.: Optical properties of the Indo-Asian haze layer over the tropical Indian Ocean, J. Geophys. Res.-Atmos., 108, 4059, doi:10.1029/2002JD002473, 2003.

Freudenthaler, V., Esselborn, M., Wiegner, M., Heese, B., Tesche, M., Ansmann, A., Müller, D., Althausen, D., Wirth, M., and Fix, A.: Depolarization ratio profiling at several wavelengths in pure Saharan dust during SAMUM 2006, Tellus B, 61, 165-179, 2009.

Griggs, D. J. and Noguer, M.: Climate change 2001: the scientific basis. Contribution of working group I to the third assessment report of the intergovernmental panel on climate change, Weather, 57, 267-269, 2002.

Huang, J., Minnis, P., Chen, B., Huang, Z., Liu, Z., Zhao, Q., Yi, Y., and Ayers, J. K.: Long-range transport and vertical structure of Asian dust from CALIPSO and surface measurements during PACDEX, J. Geophys. Res.-Atmos., 113, D23212, doi:10.1029/2008JD010620, 2008.

Huebert, B. J., Bates, T., Russell, P. B., Shi, G., Kim, Y. J., Kawamura, K., Carmichael, G., and Nakajima, T.: An overview of ACE-Asia: strategies for quantifying the relationships between Asian aerosols and their climatic impacts, J. Geophys. Res.Atmos., 108, 8633, doi:10.1029/2003JD003550, 2003.

Husar, R. B., Tratt, D., Schichtel, B. A., Falke, S., Li, F., Jaffe, D., Gasso, S., Gill, T., Laulainen, N. S., and Lu, F.: Asian dust events of April 1998, J. Geophys. Res.-Atmos., 106, 18317 18330, 2001.

Inness, A., Baier, F., Benedetti, A., Bouarar, I., Chabrillat, S., Clark, H., Clerbaux, C., Coheur, P., Engelen, R. J., Errera, Q., Flemming, J., George, M., Granier, C., Hadji-Lazaro, J., Huijnen, 
V., Hurtmans, D., Jones, L., Kaiser, J. W., Kapsomenakis, J., Lefever, K., Leitão, J., Razinger, M., Richter, A., Schultz, M. G., Simmons, A. J., Suttie, M., Stein, O., Thépaut, J.-N., Thouret, V., Vrekoussis, M., Zerefos, C., and the MACC team: The MACC reanalysis: an 8 yr data set of atmospheric composition, Atmos. Chem. Phys., 13, 4073-4109, doi:10.5194/acp-13-4073-2013, 2013.

Iwasaka, Y., Shibata, T., Nagatani, T., Shi, G. Y., Kim, Y., Matsuki, A., Trochkine, D., Zhang, D., Yamada, M., and Nagatani, M.: Large depolarization ratio of free tropospheric aerosols over the Taklamakan Desert revealed by lidar measurements: Possible diffusion and transport of dust particles, J. Geophys. Res.-Atmos., 108, 8652, doi:10.1029/2002JD003267, 2003.

Jacobson, M. Z.: Investigating cloud absorption effects: Global absorption properties of black carbon, tar balls, and soil dust in clouds and aerosols, J. Geophys. Res.-Atmos., 117, D06205, doi:10.1029/2011JD017218, 2012.

Mahowald, N. M., Muhs, D. R., Levis, S., Rasch, P. J., Yoshioka, M., Zender, C. S., and Luo, C.: Change in atmospheric mineral aerosols in response to climate: last glacial period, preindustrial, modern, and doubled carbon dioxide climates, J. Geophys. Res.Atmos., 111, D10202, doi:10.1029/2005JD006653, 2006.

Mattis, I., Ansmann, A., Müller, D., Wandinger, U., and Althausen, D.: Dual-wavelength Raman lidar observations of the extinctionto-backscatter ratio of Saharan dust, Geophys. Res. Lett., 29, 20.21-20.24, 2002.

McKendry, I., Hacker, J., Stull, R., Sakiyama, S., Mignacca, D., and Reid, K.: Long-range transport of Asian dust to the Lower Fraser Valley, British Columbia, Canada, J. Geophys. Res.-Atmos., 106, 18361-18370, 2001.

Mikami, M., Shi, G., Uno, I., Yabuki, S., Iwasaka, Y., Yasui, M., Aoki, T., Tanaka, T., Kurosaki, Y., and Masuda, K.: Aeolian dust experiment on climate impact: An overview of Japan-China joint project ADEC, Global Planet. Change, 52, 142-172, 2006.

Müller, D., Franke, K., Ansmann, A., Althausen, D., and Wagner, F.: Indo-Asian pollution during INDOEX: microphysical particle properties and single-scattering albedo inferred from multiwavelength lidar observations, J. Geophys. Res.-Atmos., 108, 4600, doi:10.1029/2003JD003538, 2003.

Müller, D., Ansmann, A., Mattis, I., Tesche, M., Wandinger, U., Althausen, D., and Pisani, G.: Aerosol-type-dependent lidar ratios observed with Raman lidar, J. Geophys. Res.-Atmos., 112, D16202, doi:10.1029/2006JD008292, 2007.

Müller, D., Mattis, I., Tatarov, B., Noh, Y., Shin, D., Shin, S., Lee, K., Kim, Y., and Sugimoto, N.: Mineral quartz concentration measurements of mixed mineral dust/urban haze pollution plumes over Korea with multiwavelength aerosol Raman-quartz lidar, Geophys. Res. Lett., 37, L20810, doi:10.1029/2010GL044633, 2010.

Murayama, T.: Optical properties of Asian dust aerosol lofted over Tokyo observed by Raman lidar, Lidar Remote Sensing in Atmospheric and Earth Sciences, edited by: Bissonnette, L. R., Roy, G., and Vallée, G., Defence R\&D Canada, Val-Bélair, 1, 331334, 2002.

Murayama, T., Masonis, S. J., Redemann, J., Anderson, T. L., Schmid, B., Livingston, J. M., Russell, P. B., Huebert, B., Howell, S. G., and McNaughton, C. S.: An intercomparison of lidarderived aerosol optical properties with airborne measurements near Tokyo during ACE-Asia, J. Geophys. Res.-Atmos., 108, 8651, doi:10.1029/2002JD003259, 2003.

Murayama, T., Müller, D., Wada, K., Shimizu, A., Sekiguchi, M., and Tsukamoto, T.: Characterization of Asian dust and Siberian smoke with multi-wavelength Raman lidar over Tokyo, Japan in spring 2003, Geophys. Res. Lett., 31, L23103, doi:10.1029/2004GL021105, 2004.

Noh, Y. M., Kim, Y. J., Choi, B. C., and Murayama, T.: Aerosol lidar ratio characteristics measured by a multi-wavelength Raman lidar system at Anmyeon Island, Korea, Atmos. Res., 86, 76-87, 2007.

Noh, Y. M., Kim, Y. J., and Müller, D.: Seasonal characteristics of lidar ratios measured with a Raman lidar at Gwangju, Korea in spring and autumn, Atmos. Environ., 42, 2208-2224, 2008.

Omar, A. H., Winker, D. M., Vaughan, M. A., Hu, Y., Trepte, C. R., Ferrare, R. A., Lee, K.-P., Hostetler, C. A., Kittaka, C., and Rogers, R. R.: The CALIPSO automated aerosol classification and lidar ratio selection algorithm, J. Atmos. Ocean. Techn., 26, 1994-2014, 2009.

Sakai, T., Shibata, T., Iwasaka, Y., Nagai, T., Nakazato, M., Matsumura, T., Ichiki, A., Kim, Y.-S., Tamura, K., and Troshkin, D.: Case study of Raman lidar measurements of Asian dust events in 2000 and 2001 at Nagoya and Tsukuba, Japan, Atmos. Environ., 36, 5479-5489, 2002.

Shimizu, A., Sugimoto, N., Matsui, I., Arao, K., Uno, I., Murayama, T., Kagawa, N., Aoki, K., Uchiyama, A., and Yamazaki, A.: Continuous observations of Asian dust and other aerosols by polarization lidars in China and Japan during ACE-Asia, J. Geophys. Res.-Atmos., 109, D19S17, doi:10.1029/2002JD003253, 2004.

Shin, S., Müller, D., Kim, Y., Tatarov, B., Shin, D., Seifert, P., and Noh, Y. M.: The retrieval of the Asian dust depolarization ratio in Korea with the correction of the polarization-dependent transmission, Asia-Pac. J. Atmos. Sci., 49, 19-25, 2013.

Sugimoto, N. and Lee, C. H.: Characteristics of dust aerosols inferred from lidar depolarization measurements at two wavelengths, Appl. Optics, 45, 7468-7474, 2006.

Sugimoto, N., Nishizawa, T., Shimizu, A., Matsui, I., and Kobayashi, H.: Detection of internally mixed Asian dust with air pollution aerosols using a polarization optical particle counter and a polarization-sensitive two-wavelength lidar, J. Quant. Spectrosc. Ra., 150, 107-113, 2015.

Sun, Y., Zhuang, G., Wang, Y., Zhao, X., Li, J., Wang, Z., and An, Z.: Chemical composition of dust storms in Beijing and implications for the mixing of mineral aerosol with pollution aerosol on the pathway, J. Geophys. Res.-Atmos., 110, D24209, doi:10.1029/2005JD006054, 2005.

Sun, Y., Zhuang, G., Huang, K., Li, J., Wang, Q., Wang, Y., Lin, Y., Fu, J. S., Zhang, W., and Tang, A.: Asian dust over northern China and its impact on the downstream aerosol chemistry in 2004, J. Geophys. Res.-Atmos., 115, D00K09, doi:10.1029/2009JD012757, 2010.

Tatarov, B., Müller, D., Shin, D. H., Shin, S. K., Mattis, I., Seifert, P., Noh, Y. M., Kim, Y., and Sugimoto, N.: Lidar measurements of Raman scattering at ultraviolet wavelength from mineral dust over East Asia, Opt. Express, 19, 1569-1581, 2011.

Tesche, M., Ansmann, A., Müller, D., Althausen, D., Mattis, I., Heese, B., Freudenthaler, V., Wiegner, M., Esselborn, M., and Pisani, G.: Vertical profiling of Saharan dust with Raman lidars 
and airborne HSRL in southern Morocco during SAMUM, Tellus B, 61, 144-164, 2009a.

Tesche, M., Ansmann, A., Müller, D., Althausen, D., Engelmann, R., Freudenthaler, V., and Groß, S.: Vertically resolved separation of dust and smoke over Cape Verde using multiwavelength Raman and polarization lidars during Saharan Mineral Dust Experiment 2008, J. Geophys. Rese.-Atmos., 114, D13202, doi:10.1029/2009JD011862, 2009b.

Wandinger, U. and Ansmann, A.: Experimental determination of the lidar overlap profile with Raman lidar, Appl. Optics, 41, 511514, 2002.

Wang, Y., Zhuang, G., Tang, A., Zhang, W., Sun, Y., Wang, Z., and An, Z.: The evolution of chemical components of aerosols at five monitoring sites of China during dust storms, Atmos. Environ., 41, 1091-1106, 2007.
Xie, C., Zhao, M., Wang, B., Zhong, Z., Wang, L., Liu, D., and Wang, Y.: Study of the scanning lidar on the atmospheric detection, J. Quant. Spectrosc. Ra., 150, 114-120, 2015.

Yi, B., Yang, P., and Baum, B. A.: Impact of pollution on the optical properties of trans-Pacific East Asian dust from satellite and ground-based measurements, J. Geophys. Res.-Atmos., 119, 5397-5409, doi:10.1002/2014JD021721, 2014.

Yu, X., Cheng, T., Chen, J., and Liu, Y.: A comparison of dust properties between China continent and Korea, Japan in East Asia, Atmos. Environ., 40, 5787-5797, 2006. 